\title{
ESCREVENDO UM LIVRO DidÁTICO DE HisTóRIA: UM ENTRELAÇAMENTO ENTRE QUESTÓES TEÓRICAS E PRÁTICAS
}

\author{
Neide Almeida Fiori*
}

\begin{abstract}
RESUMO
Esta comunicação refere-se ao livro Santa Catarina de todas as gentes: história e cultura, destinado ao $4^{\circ}$ ou 5a ano do Ensino Fundamental e que integra o Programa Nacional do Livro Didático/2010. O objetivo é analisar desafios e dilemas enfrentados. Alguns deles são de natureza operacional, como a organização da equipe, obtenção de apoio financeiro mediante a concessão de "horas de pesquisa", etc. Outros são de natureza teórica e levaram à tomada de duas decisóes fundamentais: 1) a reflexão teórica deveria estar presente, mas situada como pano de fundo em relaçáo ao texto elaborado; 2) os conceitos teóricos, todavia, deveriam ser explicitados sempre que se julgasse necessário. Ocorreram também decisóes de ordem política, como privilegiar grupos sociais que historicamente estiveram oprimidos ou limitados em sua ação.
\end{abstract}

Palavras-chave: livro didático, ensino de História, Ensino Fundamental.

Writing a History textbook: an intertwinement of theoretical and practical questions

\section{Abstract}

This communication refers to the book Santa Catarina of all peoples: history and culture, designed for the third grade of Elementary Education, and part of the Textbook National Program/2010. The proposal is to analyze challenges and dilemmas faced by such proposal. Some of an operational nature, such as staff organization, obtaining financial support through the concession of "research hours", etc. Others, of a theoretical nature, which led to the making of two fundamental decisions: 1) theoretical reflection should be present but set as a backdrop in relation to the text; 2) theoretical concepts, however, should be made explicit whenever deemed necessary. There were also decisions of a political order, such as favoring social groups that have been historically oppressed or limited in their action.

KEY WORDS: textbook, teaching of History, brazilian Elementary School.

* Professora da Universidade do Sul de Santa Catarina (UNISUL). Coordenadora o projeto de pesquisa "Educação para a cidadania global: parceiras Brasil- Cabo Verde". E-mail: neideafiori@ hotmail.com 


\section{Revista Solta a Voz, v. 20, n. 2}

\section{INTRODUZINDo o AssunTo}

O livro didático em pauta tem o título de Santa Catarina de todas as gentes: história e cultura, é destinado ao $4^{\circ}$ ou $5^{\circ}$ ano do Ensino Fundamental e integra o Programa Nacional do Livro Didático/2010. As autoras são Neide Almeida Fiori e Ivone Regina Lunardon, sendo que a primeira elaborou o presente estudo para trazer ao debate algumas questóes, a partir da perspectiva das autoras.

Enfim, planeja-se, aqui, compartilhar, explicitar um pouco as situaçóes vivenciadas pelas autoras do livro Santa Catarina de todas as gentes: história e cultura. Em suas linhas mestras, as considerações ora apresentadas são compartilhadas por ambas; mas, como não poderia deixar de ser, aqui figura, com maior destaque, a perspectiva de quem escreveu e que assume a responsabilidade pelas ideias apresentadas. Mesmo assim, no decorrer das análises talvez se misturem um pouco o "eu" e o "nós", contrariando a regra da boa escrita, segundo a qual se deve empregar o mesmo pronome na extensão de todo um texto.

Sobre o presente estudo, é possível dizer que se trata de um relato envolvendo a elaboração de um livro didático, articulado a reflexôes centradas em dois polos: os desafios da prática e as relaçóes com paradigmas teóricos, questôes que muitas vezes se interpreta como não relacionadas/ independentes entre si. Para este último entendimento, por certo colabora uma concepçáo simplista das questóes que envolvem a prática, a partir de uma tradição que não a relaciona com formas de pensar, ou, pelo menos, não cercadas de estruturas de reflexão mais sofisticadas.

Essa impressão de simplicidade é reforçada ainda pelas particularidades do livro em análise: uma estrutura de comunicação caracterizada por frases curtas organizadas em ordem direta, que demanda especial cuidado no trato com o pensamento abstrato e o emprego de analogias, com muitas ilustraçóes e um design gráfico que emprega tons coloridos. Todavia, sob diferente perspectiva de análise, essa simplicidade se revelará apenas aparente.

Dessa maneira, o objetivo principal deste texto é, percorrendo alguns caminhos, ir além dessas aparências que situam o livro didático como algo simples, simples no sentido de não apresentar maiores dificuldades ou obstáculos. Como uma contraface desse entendimento, afirma-se, a partir de situaçóes relacionadas com a experiência, que elaborar um texto didático nada tem de simples. 


\section{Relembrando o COMEÇo}

Num certo dia, por meio de um contato telefônico que se inicia na cidade de Florianópolis (SC), a Base Editora (sede em Curitiba/PR) dirigiu-me o convite para escrever um livro didático sobre a história de Santa Catarina. Inicialmente, houve contra-argumentação, afirmando que, como socióloga, até então nunca me aventurara a escrever para alunos do Ensino Fundamental; mas o convite se manteve, outros diálogos ocorreram e o entusiasmo foi surgindo. Então, com Ivone Regina Lunardon, graduada em História e por muito tempo professora de escola pública $-4^{\circ}$ ou $5^{\circ}$ ano -, assumi a responsabilidade de elaborar o livro didático.

A situação logo suscita tomada de decisões de ordem operacional (organização geral das atividades de trabalho), teórica e política, que se articulam e se entrelaçam, sendo agora as duas últimas enfocadas separadamente apenas por uma questão de didática da comunicação.

No que diz respeito às reflexôes teóricas, as autoras acordaram que era importante e que deveriam estar presentes sempre que cabível, podendo assumir duas posições: discreta ou explícita. Enfim, almejava-se construir uma narrativa destinada a alunos e docentes do Ensino Fundamental, mas sempre contemplando contribuiçóes interdisciplinares, o que aponta para diversos paradigmas. Essa expressão nos remete a Alain Touraine (2007, p. 13), para o qual um "paradigma não é só um instrumento nas mãos da ordem dominante, mas igualmente a construção de defesas, de críticas e de movimentos de liberação", o que muito se ajusta ao espírito do manual escolar que se desejava elaborar.

Essa orientação foi seguida durante o "ato de escrever". Dessa maneira, em algumas ocasióes, o referencial teórico constitui uma presença explícita, especialmente no manual do professor, ao serem abordados temas como: Nova História/Les Annales, teoria histórico-cultural, tempo histórico, cultura, brinquedos e brincadeiras infantis, teoria da avaliação, história, arte e racionalidade do mundo escolar. Em outras situaçóes, a teoria assume ares de uma presença discreta, como um pano de fundo. Nesses momentos, seguia-se um procedimento semelhante ao de Jurandir Malerba no livro A corte no exílio: civilização e poder no Brasil às vésperas da Independência (1808 a 1821). Graham, ao prefaciar o livro de Malerba (2000, p. 18), afirma que o autor havia retirado "da vista do público leitor a base teórica que usou para construir sua estrutura narrativa”. 


\section{Revista Solta a Voz, v. 20, n. 2}

Por sua vez, no âmbito das decisôes de ordem política, as autoras deliberaram por criar, e até priorizar, espaços de valorização para populaçóes que historicamente tivessem sido discriminadas - com imagem deturpada ou voz abafada ou suprimida no decorrer do processo histórico. Como consequência, uma decisão inicial foi organizar essa parte da obra em unidades de estudo específicas: uma se ocupando da população indígena e outra, da populaçáo de africanos/escravos e seus descendentes, o que não parecia então ser o usual, pelo menos a partir da bibliografia consultada.

\section{DESAFIOS - DIFICULDADES A VENCER}

Quem escreve um livro didático, além das óbvias questóes relacionadas ao conteúdo, vive imerso em desafios, isto é, cercado de circunstâncias que incitam à luta, uma luta intelectual rumo à elaboração de seu escrito. Um desafio que se colocou desde logo foi contemplar as orientaçóes do Ministério da Educação. Apresentadas com nível de grande abstração (essa observação não tem posição de crítica), exigem dos autores a descoberta de formas de implementação, de caminhos de agir que estabeleçam relaçôes entre a orientação e a realidade. Essas normas e sugestóes indicam caminhos diversos. Dessa forma e dentre outras orientaçóes, de um lado afirmam a importância de os autores estarem atentos às contribuiçóes da Nova História, o que nos conduz a March Bloch e a Les Annales. De outro lado apontam a importância de centrar os grupos populacionais da região à qual o manual escolar se destina.

Quais os principais grupos populacionais que povoaram as áreas onde atualmente é o estado de Santa Catarina? Recorde-se que o país se organizou historicamente a partir de uma população com uma cultura de base lusobrasileira e que se expande rumo ao Sul. Nessa região, os imigrantes europeus chegam a partir de 1829, as populaçóes de origem africana eram já participantes das primeiras fases do povoamento pós-descoberta e os indígenas historicamente estiveram sempre presentes (Piazza, 1983). Como relacionar situaçóes dessa ordem com as orientaçóes da Nova História, que preconiza a necessidade de serem estabelecidas relações entre o passado e o presente?

Muitas ligaçóes passado/presente são estabelecidas no decorrer do livro didático e uma ou outra será aqui enfocada como ilustraçóes de desafios enfrentados ao escrever um manual escolar. Um interessante momento 
diz respeito ao uso do botoque pelos índios Xokleng, populaçôes nômades que ocuparam uma extensa área do estado de Santa Catarina (Unidade II - Populaçóes indígenas). Para o jovem Xokleng, o uso do botoque ocorre pela primeira vez durante uma grande festa, quando o lábio inferior do menino é perfurado e um pequeno pedaço de madeira, o botoque, é introduzido no lábio inferior. Na foto abaixo (Fig. 1), o botoque pode ser visto em um jovem rosto indígena.

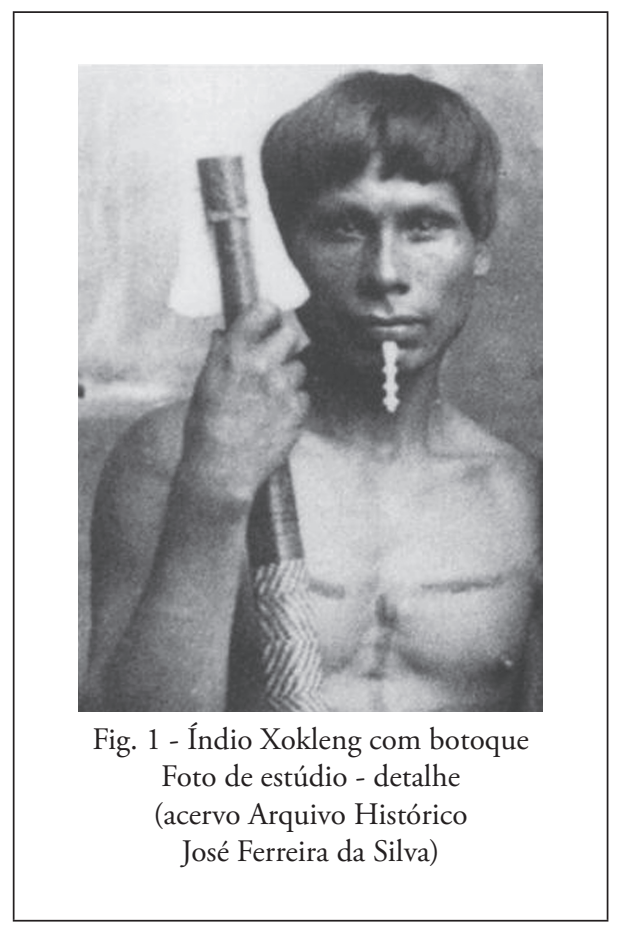

O objetivo educativo do que vem sendo exposto é estabelecer ligaçóes entre o botoque e o piercing de nossos tempos - relaçóes entre o passado e o presente. Dessa forma, no manual escolar, o diálogo com os alunos continua com o ícone "Refletindo sobre o texto". Este esclarece que a humanidade, desde muitos séculos, usa objetos de adorno que perfuram o corpo, e, a partir daí, apresentam-se consideraçóes sobre o piercing. A situação permite ao professor, em sala de aula, fundamentar uma troca de ideias com vistas a aclarar: o piercing tem, para os jovens de hoje, 


\section{Revista Solta a Voz, v. 20, n. 2}

um significado semelhante ao que tinha o botoque para os Xokleng? Em relação à temática indígena, questôes de outras ordens também foram abordadas, como o extermínio indígena, a ação protetora dos jesuítas, visualizados nos desenhos de Jean Baptiste Debret, Rugendas e outros tipos de imagens.

Outro grande e constante desafio, presente em todas as fases de elaboração do livro didático e que exigiu esforço e até mesmo obstinação, foi obter imagens para ilustrar a obra, geralmente fotografias. Podese perguntar: foi utilizada a Internet? Sim, mas essa contribuição foi a mínima possível e teve uma posição complementar ao ser situada como investigação iconográfica de caráter exploratório. Numerosas imagens faziam-se necessárias, tendo em vista propiciar apoio ao processo de ensino-aprendizagem - Santa Catarina de todas as gentes apresenta mais de 300 ilustraçóes. Sobre o assunto, as autoras acordaram, de modo específico, sobre a necessidade de, no caso de acervos particulares, somente divulgar imagens com uso autorizado (autorização expressa em documento). Outra meta, essa bastante utópica, em virtude da carência dessa informação, referia-se ao uso de imagens com o devido registro do nome do fotógrafo. A verdade é que tudo isso, embora muito louvável na perspectiva da produção científica e do atendimento às exigências legais, tornou moroso o trabalho das autoras e da equipe de apoio, por envolver intermináveis contatos telefônicos e muitas correspondências (virtuais e convencionais).

Na montagem do acervo de imagens para o livro didático, entretanto, não houve somente dificuldades. Estas eram muito atenuadas quando se utilizavam reproduçóes que tinham livros como fonte. Não era problemático elaborar a referência bibliográfica e a situação permitia atribuir méritos - ao pesquisador que identificou e analisou a imagem e ao fotógrafo que a reproduziu. Somente para aprofundar essa exemplificação, registrem-se as marcantes contribuiçóes do antropólogo Sílvio Coelho dos Santos, em Os indios Xokleng: memória visual (1997), e dos pesquisadores da Universidade de Sáo Paulo, Boris Kossoy e Maria Luiza Tucci Carneiro, com o livro $O$ olhar europeu: o negro na iconografia brasileira do século $X I X(2002)$. Imagens muito expressivas dessas obras estão agora difundidas pelo livro didático, à disposição das crianças de Santa Catarina.

No que diz respeito à situação dos africanos vindos para o Brasil como escravos, esse manual escolar reproduz anúncios de jornal da 
época em que eram oferecidos à venda; mostra os sofrimentos dessa população e o papel do "capitáo-do-mato". Mas apresenta também outra face, que permite aos alunos, os pequenos leitores, tomarem conhecimento de que atualmente existem, entre os afrodescendentes, açóes e movimentos que buscam fazer renascer laços culturais com a terra de origem - a África. Dessa maneira, o conteúdo do livro agasalha uma diversidade de perfis, como o do escravo Zumbi, verdade e mito, e, nos tempos atuais, a figura de Abdias Nascimento, que levantou a bandeira da valorização do negro.

\section{ANÚNCIO DE COMPRA DE ESCRAVOS}

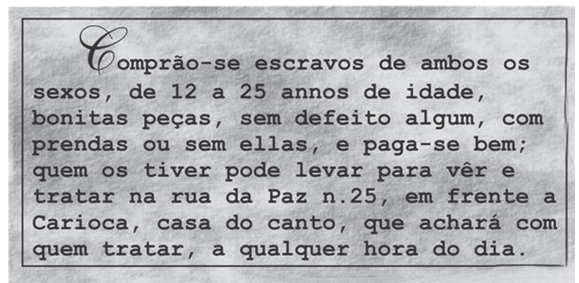

Fig. 2: Compra de escravos

Texto de anúncio de compra de escravos publicado na cidade de Desterro.

Jornal O Despertador, de 26 de janeiro de 1864

\section{DILEMAS - CAMINHOS A ESCOLHER}

Quem escreve um livro dessa natureza enfrenta muitos dilemas, situaçóes que possibilitam diversos encaminhamentos ou soluçóes. Neste sentido, algumas exemplificaçóes estão aflorando, ao sabor das lembranças. Esses dilemas exigiram decisóes que às vezes envolviam um contexto aparentemente muito simples, como o que ocorreu durante a organizaçáo final da unidade denominada Chegam os imigrantes, complementada com fértil ilustração (Unidade V). Nesse momento, colocou-se a seguinte questão: qual grupo étnico-imigrante seria adequado enfocar primeiro? Registre-se que o estado de Santa Catarina teve, durante muito tempo, sua imagem simbólica associada aos grupos imigrantes alemães e italianos: "estado de alemães" ou "regiâo de italianos", dizia-se. 
Uma análise da cronologia indicava que, entre os diversos grupos sociais que imigraram para Santa Catarina, os alemães deveriam ser focalizados inicialmente, pelo fato de terem sido os primeiros a chegar. Ou seria mais adequado iniciar a unidade analisando os italianos, em funçáo de reconhecidamente constituírem o grupo mais numeroso? Decidida essa questão, a seguir pensava-se então: o livro apresentaria, aos seus pequenos leitores, os outros grupos de imigrantes que vieram para as terras de Santa Catarina - poloneses, ucranianos, gregos, sírios e sírio-libaneses, etc. Tudo racionalmente correto, a partir dos critérios acima colocados.

No entanto, ao analisar a versão preliminar do citado capítulo, já com as devidas ilustraçóes, as autoras perceberam que algo não estava bem - não se ajustava à decisáo política de privilegiar os grupos sociais de alguma forma mais desfavorecidos. Afirma-se isso porque, ao analisar a organização do capítulo, embora com apoio na racionalidade, percebeu-se que o texto acabava colocando fortes tons de valorização nos grupos imigrantes de origem alemã e italiana. No livro didático, esses seriam os primeiros imigrantes a serem enfocados e longamente analisados; e, como se sabe, a disposição no espaço, mesmo quando se trata de uma página de manual escolar, apresenta facetas ideológicas. Nesse contexto, os demais grupos imigrantes, por certo, seriam percebidos apenas como "os outros", expressão que poderia estar associada à ideia de "menor importância".

O que fazer, então? Esse era um dilema a ser resolvido. A solução encontrada foi descrever inicialmente os grupos imigrantes considerados como os mais "estranhos", ou seja, os mais "fora do comum" e que muito dificilmente estavam associados simbolicamente à imagem de Santa Catarina. Dessa maneira, o capítulo Chegam os imigrantes sofreu sérias alteraçóes (menos de conteúdo e mais de disposição gráfica) e acabou apresentando, inicialmente, um casal de imigrantes que, sentados em grande estilo, posou para uma foto, que é do ano de 1918 - um imigrante belga e sua esposa inglesa, que moravam em uma região chamada Ilhota, no conhecido Vale do Itajaí (Fig. 3). Incluiu-se ainda a fotografia de uma família de imigrantes russos, que se radicou na regiáo Sul do estado. Na mesma página, posando com suas roupas domingueiras, um jovem casal que viera de uma regiáo situada próximo do mar Báltico, a longínqua Pomerânia, que passou por muitas vicissitudes em suas fronteiras, o que muitas vezes fez mudar a nacionalidade dessa população; muitos deles entraram no Brasil sob a nacionalidade alemã. 


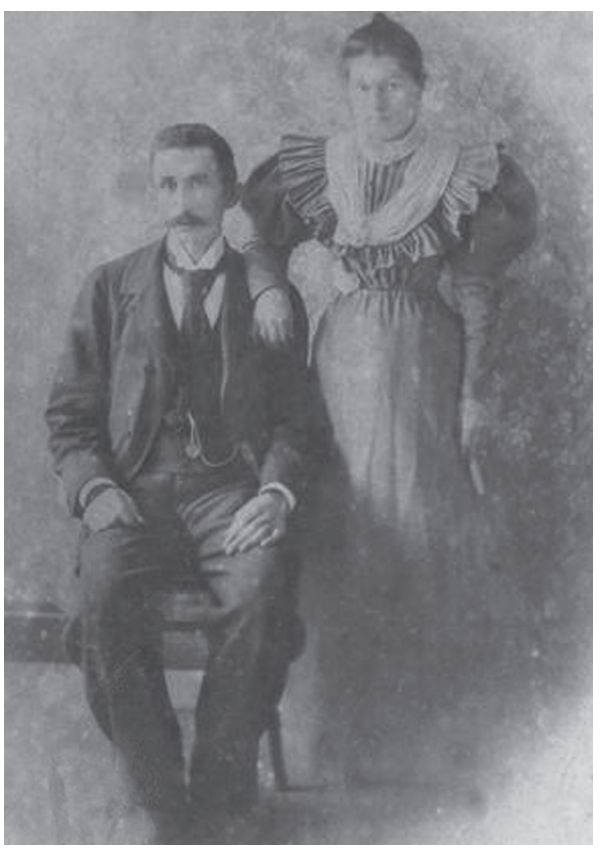

Fig. 3: Ilhota - ano 1918

Imigrante belga Izidoro de Coninck e sua esposa inglesa Izabel Gower Leslie.

Acervo F. Coninck

Uma colônia belga foi fundada no ano de $1846 \mathrm{em}$ Ilhota, no vale do Rio Itajaí.

A partir daí, o capítulo Chegam os imigrantes continuou fluindo e depois, por toda importância que têm e que não se pensou em diminuir, foram enfocados os grupos imigrantes alemães e italianos. Com o auxílio dessa estratégia comunicativa, tem-se a expectativa de haver colaborado, mesmo que de forma sutil, para mostrar aos alunos a diversidade étnica presente na composiçáo populacional da terra catarinense. O Parecer do Ministério da Educação apresenta palavras favoráveis nesse sentido, pois, ao analisar Santa Catarina de todas as gentes: história e cultura, aponta:

Contempla princípios éticos e de cidadania. Promove a inclusão de diversos grupos étnicos, dando especial ênfase à promoção do grupo afro- 


\section{Revista Solta a Voz, v. 20, n. 2}

descendente, ao apresentar destaques a ações de pessoas ou grupos que possam servir como exemplo afirmativo às crianças e aos jovens. É construída numa perspectiva que busca contemplar os diferentes grupos étnicos e sociais que habitam o estado de Santa Catarina.

Visa ao rompimento com estereótipos e visóes que diminuem grupos étnicos, regióes do estado e a própria noção de sujeito histórico. Procura centrar a narrativa para além de alguns personagens em detrimento de outros, dando ênfase a açôes mais coletivas. Dessa forma, alunos de alguns grupos étnicos encontrarão na obra exemplos afirmativos que poderão auxiliá-los na sua construção como cidadãos. (Brasil, 2009, p. 252)

As colocaçóes anteriores indicam que a estrutura narrativa, apoiada em decisóes teóricas e políticas, às quais já foram feitas referências, possibilitou expressar uma posição de respeito aos diversos grupos étnicos que integram a realidade social do estado de Santa Catarina.

\section{A Cultura Como uma Questấo}

O livro didático Santa Catarina de todas as gentes: história e cultura destina-se ao $4^{\circ}$ ou $5^{\circ}$ ano do Ensino Fundamental. Trata-se de um livro regional, que foi escrito buscando afastar-se do modelo da história estritamente positivista/tradicional, que se ocupa com a busca da "verdade histórica”, valorizando as dimensóes políticas da realidade social, no caso, dirigidas a personagens importantes da humanidade - a chamada "história oficial". Pelo contrário, identifica-se mais com as ideias de March Bloch, que, em $A$ apologia da história: ou o ofício do historiador, endossa uma "concepção da história-problema ou da história interdisciplinar" - história-problema entendida como algo que deve ser objeto de troca de ideias e de debate (Bloch, 2001, p. 32). Uma postura que se harmoniza também com a do historiador Edward Carr (2002, p. 29), que valoriza as proximidades disciplinares afirmando: "Quanto mais sociológica a história se torna, e quanto mais histórica a sociologia se torna, melhor para ambas".

Quase como um desdobramento dessas formas de pensar, evidencia-se que história e cultura se entrelaçam intimamente, ensinamento que tem raízes em autores como Roger Chartier, que escreveu $A$ história cultural: entre práticas e representaçóes, livro considerado como uma das reflexóes 
pioneiras sobre o tema. Enfim, as análises que envolvem história e cultura ajudam a perceber como, nos mais diferentes lugares e momentos, uma determinada realidade social é concebida, construída e passa a fazer parte da vida social. Ou seja,

[...] as percepções do social não são de forma alguma discursos neutros: produzem estratégias e práticas (sociais, escolares, políticas) que tendem a impor uma autoridade à custa de outros, por elas menosprezados, a legitimar um projecto reformador ou a justificar, para os próprios indivíduos, as suas escolhas e condutas. (Chartier, 1990, p. 17)

Por essa linha de reflexão, poder-se-ia referir a outros autores, como Erving Goffman (1988), Michel Foucault (1993) e Pierre Bourdieu. Este é autor de $O$ poder simbólico (1989), que, ao longo de décadas, vem "influenciando numerosas pesquisas sociológicas, antropológicas e históricas” (Bethencourt; Curto, 1989, p. 1). Nesse livro, afirma que para descobrir o poder simbólico - expressão importante e que dá título à obra - exigem-se exercícios de olhar.

É necessário saber descobri-lo onde ele se deixa ver menos, onde ele é mais completamente ignorado, portanto [menos] reconhecido: o poder simbólico é, com efeito, esse poder invisível o qual só pode ser exercido com a cumplicidade daqueles que náo querem saber que lhe estão sujeitos ou mesmo que o exercem. (Bourdieu, 1989, p. 7-8)

Não se pretende afirmar, contudo, que toda simbologia é assim tão problemática em seu desvendamento; muitas vezes até faz parte do nosso cotidiano, como as relacionadas com o uso de alianças de compromisso/ casamento, situação impregnada de forte poder simbólico e que, naturalizada, adquire ares de algo autoevidente: "Ultrapassando a medida da pura razão, o símbolo quebra os quadros lógicos e encerra contrários numa mesma visão. Os anéis da aliança enunciam simultaneamente a ligação livremente aceita e as cadeias institucionais que limitam as liberdades individuais" (Rivière, 1989, p. 220).

O poder simbólico costuma ser identificado em "universos" ou "sistemas simbólicos" específicos, como a arte, a língua, a educação, a religião - simbologia que frequentemente se apresenta de forma bas- 


\section{Revista Solta a Voz, v. 20, n. 2}

tante oculta. Além desse fato relacionado com o "ocultamento", saliente-se que os símbolos envolvidos nesse estilo de poder contribuem significativamente para a integração social. Daí a especial importância das ações educativas impregnadas de poder simbólico nos primeiros anos de escolaridade, em virtude da importância de, nessa instância de ensino, difundirem-se valores, crenças e atitudes que estimulam a coesão social.

Essa fase da escolaridade constitui um espaço pedagógico especialmente centrado na busca da homogeneidade social. O que Émile Durkheim designa como "coesão por semelhança" (ou "solidariedade mecânica") e que envolve um "conjunto de crenças e de sentimentos comuns à média dos membros de uma mesma sociedade, formando um sistema determinado que tem vida própria; pode-se chamá-lo de consciência coletiva ou comum" (Rodrigues, 1978, p. 74). Conjunto de crenças, sentimentos, valores que, como já visto, são especialmente importantes no ensino destinado às primeiras séries. Em análises que lembram essa ordem de reflexôes, uma voz recente é a de João Valdir Alves de Souza (2007), que, com conhecimentos de mestre em Educação e doutor em História e Filosofia da Educação, relaciona a chamada "coesão por semelhança" e a "função homogeneizadora" da educação e ilustra seu pensamento apontando o chamado núcleo comum da LDB.

Outra forma de evidenciar fatos dessa ordem é analisar, na escola primária tradicional de cunho nacionalista, as suas responsabilidades relacionadas com a coesão social, cabendo-lhe desenvolver no alunado uma "cultura comum e uma ideologia cívica, um conjunto de critérios e aspiraçôes, sentimentos e ideais que unam a população na sua terra natal" (Smith, 1997, p. 24). E, ao cumprir essas responsabilidades, apresenta-se muito forte a presença do poder simbólico e o emprego de símbolos. Analise-se o Hino à Bandeira Nacional, com letra de Olavo Bilac e que nas décadas de 1940/1950 era muito cantado nas escolas brasileiras:

\section{Hino à Bandeira}

Salve, lindo pendão da esperança,

Salve, símbolo augusto da paz!

Tua nobre presença à lembrança

A grandeza da Pátria nos traz. 
Recebe o afeto que se encerra

Em nosso peito juvenil,

Querido símbolo da terra,

Da amada terra do Brasil!

Em teu seio formoso retratas

Este céu de puríssimo azul,

A verdura sem par destas matas,

E o esplendor do Cruzeiro do Sul.

Recebe o afeto que se encerra, etc.

(Brasil, 2009)

As questóes que vêm sendo analisadas valorizam o estudo das relaçôes entre mundo do simbólico e cultura, uma postura que na atualidade tem no antropólogo norte-americano Clifford Geertz possivelmente a sua mais expressiva figura. A contribuição teórica desse autor é multifacetada e defende o conceito de cultura não como inserido em uma ciência experimental em busca de leis, mas como uma ciência interpretativa em busca de significados, chegando a afirmar: "O conceito de cultura que eu defendo é essencialmente semiótico" (Geertz, 1989, p. 4) - os fenômenos culturais considerados como sistemas de significação e os espaços dessa "significação" relacionam-se intimamente com o mundo do simbólico. Essa foi a trilha seguida pelo livro didático que ora se analisa: a cerimônia entre os índios Xokleng (já visto), que tem seu auge com a introdução do botoque no lábio inferior do adolescente, constitui um símbolo tribal usado pelos homens.

Quanto ao conceito de cultura endossado na elaboração do livro didático e do respectivo manual do professor, alguns desafios básicos se colocaram: 1) clarear para os docentes o fato de estar sendo empregado um conceito antropológico de cultura, e não o conceito de cultura usado no âmbito do senso comum, que o associa a instrução, refinamento de modos e gostos; 2) definir o paradigma teórico de cultura, a ser endossado no decorrer de toda a estruturação dos manuais escolares em questão. Esse fato gerou andanças intelectuais que não cabem aqui detalhar, mas que nos conduziram ao conceito de cultura do sociólogo Raymon Firth, que afirma que quando "se considera a sociedade como um conjunto organizado de indivíduos com um determinado modo de vida, a cultura é esse modo de vida" (apud Kluckhohn, 1987, p. 291). A partir dessa ótica intelectual, estruturou-se a 
unidade do livro escolar denominada Maneiras de Viver, que agasalhou dentro de si os hábitos alimentares, as formas arquitetônicas das construçóes e, inclusive, as festas típicas como manifestaçôes da cultura - manifestações das diferentes formas de viver típicas do povo de Santa Catarina.

Outras consideraçóes poderiam aqui ser tecidas a respeito do livro didático, como o fato de chamar a atenção dos docentes para a importância de adequadamente entenderem determinado tempo histórico, procurando controlar erros do anacronismo de se interpretar o passado a partir dos mesmos valores e critérios com que se interpreta o presente, ou vice-versa.

Assim, também as brincadeiras infantis foram enfocadas como manifestações culturais, inspiradas na lição de Gilles Brougère em Brinquedos e Companhia (2004). Neste livro, o leitor é levado a navegar entre histórias de Power Rangers, Ursinhos Carinhosos, Barbie e Pokémon, num estilo agradável e envolvente. Para ilustrar como um tipo de caminho pode levar a outro, Brougère $(2004$, p. 12) relata que, aproximadamente no final dos anos 1970 e bem ao acaso, os brinquedos entraram em sua vida de trabalho ao participar do projeto de pesquisa etnográfico Jogos e Brinquedos, coordenado por Robert Jaulin, antropólogo francês que iria se tornar um dos mais expressivos críticos da forma como os países latino-americanos conduziam a política indigenista e suas propostas. No decorrer do Congresso Internacional Americanista de Stuttgard, a atuação de Jaulin levou à popularização do termo "etnocídio", testemunho de uma contundente ação política. Outro foi o caminho tomado por Gilles Brougère, que, desde a participação na citada investigação etnográfica, descobriu os brinquedos de uma forma diferente daquelas dos tempos de infância: como objeto de estudo e de investigação. E afirma: "Mais de duas décadas depois continuo a trabalhar no mesmo assunto sem ter nunca um sentimento de saturação" (Brougère, 2004, p.13). Seus estudos fornecem importante contribuição para a valorização e o desenvolvimento de uma posição de respeito à atividade lúdica infantil, situando as crianças como atores sociais, e não apenas como objetos-alvo da socializaçáo.

Aliás, as crianças inseridas no contexto da socialização têm sido um enfoque muito presente em diversos estudos. E, nessas ocasióes, uma personagem sempre referida é Émile Durkheim, muitas vezes apontando-se o conceito de educação que figura em sua obra Éducation et Sociologie (1966) e poucas vezes transcrevendo-o e analisando-o. Para Durkheim (1978, p. 41), 
A educação é a ação exercida, pelas gerações adultas, sobre as gerações que não se encontram ainda preparadas para a vida social; tem por objetivo suscitar e desenvolver, na criança, certo número de estados físicos, intelectuais e morais, reclamados pela sociedade política, no seu conjunto, e pelo meio especial a que a criança, particularmente, se destina.

Esse autor intercambia as expressóes educação e socialização, considerando a educação como "uma socialização metódica da jovem geração" (Durkheim, 1978, p. 41). Essa concepção durkheimiana tem retornado, com frequência, nos estudos que se ocupam em analisar a sociologia da infância num contexto que lhe atribui relação e/ou mesmo responsabilidade pela marginalização do tema como objeto de estudo. Essas afirmativas partem de autores de prestígio internacional como Régine Sirota, por exemplo, que no artigo L'émergence d'une sociologie de l'enfance: évolution de l'objet, évolution du regard, divulgado na revista Éducation et Societés e cuja tradução foi publicada no Brasil em 2001, diz:

A sociologia em geral, particularmente a sociologia da educação, seja ela de língua francesa ou inglesa, permaneceu durante muito tempo implicitamente circunscrita a essa definição durkheimiana, desenvolvendo, em perspectivas autônomas de pesquisa, diferentes olhares sobre a infância, configurados segundo os modos de apreensão institucional do objeto social. Estes são, pois, os pontos de partida do apagamento da infância ou de sua marginalização. (Sirota, 2001, p. 09)

Outros autores, como Manuel Jacinto Sarmento, em seu estudo Sociologia da infância: correntes e confluências, revelam entendimentos diferentes, com uma postura valorativa, do pensamento do sociólogo francês:

[...] a consideração da infância como geração sobre a qual os adultos realizam uma ação de transmissão cultural e de "socialização" constituiu-se como objeto de uma das mais importantes obras do início do pensamento sociológico: o da teoria da socialização de Émile Durkheim. (Sarmento, 2008, p. 18)

Faz-se importante salientar ainda que a partir desse artigo de Sarmento é possível inferir que ele não considera a sociologia ainda "ancorada" no conceito durkheimiano de "socialização" - um conceito elaborado no 


\section{Revista Solta a Voz, v. 20, n. 2}

início do século XX, divulgado por Durkheim em publicações e no decorrer de aulas e palestras entre os anos 1902 a 1911 (Cf. Fauconnet, 1966). Acrescente-se, também, que Sarmento (2008, p. 20) considera necessário "um trabalho reconfigurador do conhecimento" referente à questão da socialização, trabalho que entende em andamento, e, nesse sentido, muito valorizando a contribuição dos psicólogos e dos sociólogos. Ele afirma que, mesmo havendo agora a necessidade de construção científica do objeto social infância, "a Sociologia nem por isso deixou de considerar a inserção social das crianças" (Sarmento, 2008, p. 20). E estende suas consideraçôes apontando que, a partir de Durkheim, o conceito de socialização passou por diferentes versóes e revisóes, dele se ocupando diversos autores, como Parsons e Bales, Bourdieu e Passeron, e Peter Berger e Thomas Luckmann.

A referência a esses autores nos permite agora delinear contribuiçóes da sociologia para a infância como objeto científico a partir de diversificados campos teóricos, como Bourdieu e Passeron com a teoria da reprodução, e Peter Berger e Thomas Luckmann com a obra A construção social da realidade (1 $1^{\text {a }}$ edição, em inglês, de 1962). Esta última marca o campo da sociologia do conhecimento no sentido de também abranger o conhecimento do senso comum e a realidade da vida cotidiana como fontes de estudo da sociedade. No livro, ao tratar da interiorização da realidade, os autores desdobram suas análises em socialização primária e socialização secundária, e todo o estudo se apoia no entendimento de que "sendo a sociedade uma realidade ao mesmo tempo objetiva e subjetiva, qualquer adequada compreensão teórica relativa a ela deve abranger ambos estes aspectos" (Berger; Luckmann, 1978, p. 173). Como exemplo de interseçóes entre campos do conhecimento, pode-se referir a questôes analisadas no artigo $A$ socialização das crianças na psicologia piagetiana e os seus prolongamentos sociológicos (Dubar, 1997), que aqui se cita apenas como ilustração.

Em tempos mais recentes, autores como Maria da Graça Jacintho Setton escreveram sobre o tema. Setton (2005, p. 335), em artigo que tem o instigante título de $A$ particularidade do processo de socialização contemporâneo, afirma que ao refletir sobre a emergência de novos modelos de socialização relaciona-os com "o processo de construção da identidade social e pessoal do indivíduo na atualidade, a partir das transformaçôes sofridas no interior das agências tradicionais da educação".

Voltando aos estudos sobre a infância, há posiçóes que valorizam a sociologia da infância e/ou os estudos que se centram na questão da 
socialização e ainda "pesquisas que defendem a escuta e enfocam as infâncias e as culturas infantis, com base em referenciais teórico-metodológicos" (Delgado; Müller, 2005, p. 353). Nesse contexto de ideias em ebulição, emerge, com importância, o conceito de cultura. Um novo conceito de cultura, no sentido de ser desvinculado (ou bastante desvinculado) do tradicional entendimento antropológico que relaciona o termo a um sistema de valores e normas de comportamento que orientam a prática. $\mathrm{O}$ conceito de cultura se amplia, difundindo-se nos mais variados recantos da vida social, e passa a se fazer presente em situaçóes antes inusitadas, abrangendo a chamada cultura de massas e, das mais variadas formas, o mundo da escolaridade.

O modelo escolar do mundo ocidental tem sido considerado, em sua forma típica, como expressão de organização racional, o que nos leva às ideias de Max Weber.

O traço característico do mundo em que vivemos é a racionalização. [...] O empreendimento econômico é racional, a gestão do Estado pela burocracia também. A sociedade moderna tende toda ela à organizaçáo zweckrational, e o problema filosófico do nosso tempo, problema eminentemente existencial, consiste em delimitar o setor da sociedade em que subsiste e deve subsistir uma ação de outro tipo. (Aron, 1999, p. 449)

Considera também que um problema existencial do nosso tempo consiste em deliminar os setores da sociedade em que existe, ou deve existir, um outro tipo de ação, isto é, de açôes que não sejam racionais, no sentido weberiano.

Preocupações dessa ordem, apoiadas em uma filosofia existencial, podem ser identificadas no processo de escolarizaçáo em geral e mesmo em situaçóes específicas, sempre buscando atenuar a racionalidade imposta pela escola: na valorização da arte, em suas diversas formas de manifestação, ou dos brinquedos e das brincadeiras infantis. Agasalhados por essa perspectiva, brinquedos e brincadeiras como bola de gude, cabra-cega, pipa e pandorga, festa junina e bolinha de sabão foram incluídos no livro didático Santa Catarina de todas as gentes, a partir da reprodução de obras de arte expressas em "óleo sobre tela" e aquarelas, o que somente foi possível porque pintores como Willy Zumblick e Salet Liñera colaboraram, autorizando formalmente o uso dessas imagens. E, dessa maneira, o manual escolar 
chega às suas páginas finais, enfocando a leveza das brincadeiras infantis percebidas como manifestaçóes culturais.

\section{REFERÊNCIAS}

ARON, Raymond. As etapas do pensamento sociológico. São Paulo: Martins Fontes, 1999.

BERGER, Peter L.; LUCKMANN, Thomas. A construção social da realidade. 4. ed. Petrópolis: Vozes, 1978.

BETHENCOURT, Francisco; CURTO, Diogo Ramada. Nota de apresentação. In: BOURDIEU, Pierre. O poder simbólico. Lisboa: DIFEL; Rio de Janeiro: Bertrand, 1989, p.1-5.

BLOCH, March. A apologia da história: ou o ofício do historiador. Rio de Janeiro: Jorge Zahar, 2001.

BOURDIEU, Pierre. O poder simbólico. Lisboa: DIFEL; Rio de Janeiro: Bertrand, 1989.

BRASIL. Exército Brasileiro. Hino à Bandeira Nacional. Disponível em: <http://www.exercito.gov.br/01inst/Hinoscan/bandeira.htm>. Acesso em: nov. 2009.

- Ministério da Educação, Secretaria de Educação Básica. Guia de livros didáticos - PNLD 2010: História. Brasília: 2009.

BROUGÈRE, Gilles. Brinquedos e companhia. São Paulo: Cortez, 2004.

CARR, Edward Hallet. O que é história? 8. ed. São Paulo: Paz e Terra, 2002.

CHARTIER, Roger. A história cultural: entre práticas e representações. Lisboa-Portugal: DIFEL; Rio de Janeiro: Bertrand, 1990.

DELGADO, Ana Cristina Coll; MÜLLER, Fernanda. Sociologia da infância: pesquisa com crianças. Educação \& Sociedade, v. 26, n. 91, p. 351360, maio/ago. 2005.

DUBAR, Claude. A socialização: construção das identidades sociais e profissionais. Porto: Porto Editora, 1997. 
DURKHEIM, Émile. Educação e Sociologia. 11. ed. São Paulo: Melhoramentos; Rio de Janeiro: Fundação Nacional de Material Escolar, 1978.

FAUCONNET, Paul. Introduction: l'ouvre pégagogique de Durkheim. In: DURKHEIM, Émile. Éducation et Sociologie. 2 ed. Paris: Presses Universitaires de France, 1966, p. 01-30.

FIORI, Neide Almeida; LUNARDON, Ivone Regina. Santa Catarina de todas as gentes: história e cultura. 2. ed. Curitiba: Base, 2008. 280 p.

- Santa Catarina de todas as gentes: história e cultura - Manual do professor. 2. ed. Curitiba: Base, 2008. 360 p.

FOUCAULT, Michel. Vigiar e punir: nascimento da prisão. 10. ed. Petrópolis: Vozes, 1993.

GEERTZ, Clifford. A interpretação das culturas. Rio de Janeiro: LTC, 1989.

GOFFMAN, Erving. Estigma: notas sobre a manipulação da identidade deteriorada. 4. ed. Rio de Janeiro: Guanabara, 1988.

KLUCKHON, Clyde. Cultura. Dicionário de Ciências Sociais. 2. ed. Rio de Janeiro: Editora da Fundação Getúlio Vargas, 1987, p. 290-292.

KOSSOY, Boris; CARNEIRO, Maria Luiza Tucci. O olhar europeu: o negro na iconografia brasileira do século XIX. São Paulo: EDUSP, 2002.

MALERBA, Jurandir. A corte no exílio: civilização e poder no Brasil às vésperas da Independência (1808-1821). São Paulo: Companhia das Letras, 2000 .

PIAZZA, Walter Fernando. Santa Catarina: sua história. Florianópolis: Editora UFSC; Lunardelli, 1983.

RIVIÈRE, Claude. As liturgias politicas. Rio de Janeiro: Imago, 1989.

RODRIGUES, Jose Albertino. Émile Durkheim: sociologia. São Paulo: Ática, 1978.

SANTOS, Sílvio Coelho dos. Os indios Xokleng: memória visual. Florianópolis: Ed. da UFSC; Itajaí: Ed. da UNIVALI, 1997.

SARMENTO, Manuel Jacinto. Sociologia da infância: correntes e confluências. In: SARMENTO, Manuel Jacinto; GOUVEA, Maria Cristina 


\section{Revista Solta a Voz, v. 20, n. 2}

Soares de (Orgs.). Estudos da infância: educação e práticas sociais. Petrópolis: Vozes, 2008, p. 17-39.

SETTON, Maria da Graça Jacintho. A particularidade do processo de socialização contemporâneo. Tempo Social, Revista de Sociologia da USP, v. 17, n. 2, p. 335-350, nov. 2005.

SIROTA, Régine. Emergência de uma Sociologia da infância: evolução do objeto e do olhar. Cadernos de Pesquisa, n.112, p. 7-31, mar. 2001.

SOUZA, João Valdir Alves de. Introdução à sociologia da educação. Belo Horizonte: Autêntica, 2007.

Recebido em: 30 jun. 2009 Aceito em: 01 nov. 2009 